\title{
A Indústria da Vida em Goiás
}

Com pouco mais de três décadas de existência, as indústrias farmacêuticas de Goiás construíram o segundo maior parque industrial farmacêutico de produção de medicamentos do Brasil e da América Latina. Edificaram mais de $600.000 \mathrm{~m}^{2}$ de área industrial dentro das mais rigorosos normas de regulação nacional e internacional. Produzem medicamentos genéricos, similares, isentos de prescrição, medicamentos de referência, soluções parenterais de pequenos e grandes volumes e produtos médico hospitalares que, sob várias formas de comercialização, entregam em todo Brasil, e em vários países no exterior, mais de um bilhão e meio de unidades ao ano, prontos para o consumo, e milhões de produtos médico hospitalares, todos com o melhor preço industrial do Brasil, tendo como principal fator de competitividade a produtividade num moderno parque industrial.

A Indústria Farmacêutica goiana é de tecnologia de ponta e de alta responsabilidade, pois preservam e salvam vidas. Os investimentos são constantes e significativos que somou um bilhão e meio de reais nos últimos três anos e está confirmado mais dois bilhões e meio de reais para os próximos cinco anos. Os departamentos de pesquisa e desenvolvimento geram inovações incrementais e radicais em parcerias com a Academia em geral, e com o Serviço Nacional de Aprendizagem Industria (SENAI) em particular.

Colocar um medicamento no mercado requer um grande esforço técnico e financeiro. Com a aceitação da Agência Nacional de Vigilância Sanitária (ANVISA) como membro (única da américa latina) no International Conference on Harmonisation (ICH) of Technical Requirements for Registration of Pharmaceuticals for Human Use, onde participam as agências sanitárias internacionais de primeira grandeza que se dedicam a harmonizar o regulatório para produção de medicamentos de uso humano e no Pharmaceutical Inspection Co-Operation Scheme (PIC/S) - apenas três países da américa latina - que se dedicam a harmonizar as normas de inspeção para a Certificação de
Boa Práticas de Fabricação (CBF), as indústrias goianas alcançaram os mais rigorosos padrões de qualidade equiparados com os países do primeiro mundo.

Nestes anos de pandemia, as indústrias farmacêuticas goianas aceitaram e venceram o desafio de manter o mercado abastecido e lançando medicamentos para o KITCOVID que contribuiu para salvar as vidas de milhões de Brasileiros que foram infectados. As contratações de pessoal avançaram $13 \%$ para atender as demandas dos hospitais e farmácias. Atualmente o parque emprega 15.000 trabalhadores diretos e formou um Arranjo Produtivo Local (APL), com dezenas de fornecedores de serviços tecnológicos, materiais de embalagem, terceirizações e pesquisa.

O SENAI se posiciona estrategicamente na formação de técnicos em química, e aperfeiçoamento de técnicas de produção farmacêutica bem como na formação de mão de obra especializada para o setor. O futuro da indústria farmacêutica mundial está focado nos medicamentos biológicos e monoclonais onde algumas indústrias goianas estão investindo para melhorar a vida dos brasileiros e continuar a elevar sua expectativa de vida com qualidade. Em 1945 a expectativa de vida do cidadão brasileiro era de apenas 45,6 anos e em 2020 passou para 76,7 anos. Esta foi a maior inovação em saúde no Brasil e as indústrias farmacêuticas goianas fazem parte com muito orgulho.

\section{Marçal Soares}

\author{
Sindicato das Indústrias Farmacêuticas de Goiás.
}

E-mail: marcal@sindifargo.com.br 